\title{
Corrosion Protection Mechanism of Polyaniline Blended Organic Coating on Steel
}

\author{
S. Sathiyanarayanan, ${ }^{\mathrm{z}}$ R. Jeyaram, S. Muthukrishnan, and G. Venkatachari
}

Central Electrochemical Research Institute, Karaikudi-630 006, India

Epoxy-coal tar coatings are widely used to protect steel structures exposed to marine atmosphere due to their good barrier property. However, the presence of micropores and microcracks formed during the coating formation leads to failure of the coating due to permeation of corrosive ions. In recent years, it has been established that the coatings containing polyaniline (PANI) is able to protect pinholes and defects due to its passivating ability. Hence, a study has been made on the effect of polyaniline content (1 and $3 \%$ ) in epoxy-coal tar coating on the corrosion protection of steel in $3 \% \mathrm{NaCl}$ solution by electrochemical impedance spectroscopy (EIS) studies. Both phosphate- and chloride-doped polyanilines were prepared by a chemical oxidative polymerization method. From EIS studies, it has been found that the resistance value of the coatings containing 1 and $3 \%$ phosphate-doped polyaniline and 3\% chloride-doped polyaniline pigmented coatings are $\sim 10^{9} \Omega \mathrm{cm}^{2}$ even after 90 days exposure to $\mathrm{NaCl}$ solution, which are two orders high in comparison to that of conventional coal tar epoxy coatings. Besides, the conducting state of polyaniline has been found to be decreased after exposure to $\mathrm{NaCl}$ solution due to redox property of PANI. X-ray photoelectron spectroscopy studies have shown that polyaniline forms a complex layer with iron beneath the coating along with iron oxide. (C) 2009 The Electrochemical Society. [DOI: 10.1149/1.3073874] All rights reserved.

Manuscript submitted August 18, 2008; revised manuscript received December 29, 2008. Published February 4, 2009.

Epoxy-coal tar coatings are widely used for corrosion protection of steel structures exposed to marine atmosphere due to their good barrier property. However, the lifetime of these coatings is decreased due to the formation of micropores and microcracks when epoxy resin and coal tar are cross-linked with hardeners. In recent years, it has been established that the presence of polyaniline (PANI) in organic coating on steel is able to passivate the pinholes and coating defects by passivation of iron exposed. ${ }^{1,2}$ Besides, several studies have shown that PANI-containing coatings are able to protect steel more effectively due to its passivation ability. ${ }^{3-22}$ Recently, it is shown that the addition of a small amount of titanium powder in an epoxy-coal tar coating system is able to improve the corrosionresistance property of the coating. ${ }^{23}$ Furthermore, it has been reported that the dopants in PANI play an important role in corrosion protection due to the formation of an iron-dopant secondary layer. ${ }^{8,10}$ Hence, a study has been made on the effect of the addition of polyaniline with phosphate and chloride dopants in the epoxycoal tar system on the corrosion-protection performance of steel in sodium chloride solution by the electrochemical impedance spectroscopy (EIS) method in order to elucidate the role of inhibitive phosphate and corrosive chloride dopants.

\section{Experimental}

Preparation of polyaniline-phosphate (PANI-PO $\mathrm{O}_{4}$ and polyaniline-chloride (PANI-Cl) pigments. - One molar of distilled aniline was dissolved in $500 \mathrm{~mL}$ of $1 \mathrm{M}$ solution of phosphoric acid or $1 \mathrm{M}$ solution of hydrochloric acid. Precooled $1 \mathrm{M}$ solution of ammonium persulfate was added dropwise to the precooled aniline acid mixture for $\sim 90 \mathrm{~min}$. The reaction was conducted at $5 \pm 1{ }^{\circ} \mathrm{C}$. After the addition, the stirring was continued for $2 \mathrm{~h}$. A dark-greencolored conducting polyaniline was filtered and washed with distilled water to remove residual acid content. The polymer was dried in an oven at $80^{\circ} \mathrm{C}$. The dried polyaniline was finely ground in mortar and then used as pigment.

Characterization of polyaniline pigment.- The polyaniline was characterized by Fourier transform IR (FTIR), X-ray diffraction (XRD), and conductivity measurements. The experimental details were given in earlier publications. ${ }^{16,17}$

Preparation of polyaniline containing epoxy-coal tar paint.The epoxy resin solution was prepared by dissolving solid epoxy having an epoxy equivalent weight of 450-550 in xylene. The coal tar was added to the epoxy resin and mixed thoroughly. The ratio of

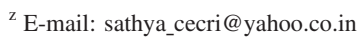

epoxy and coal tar was 1:3 by weight. The PANI having chloride and phosphate as dopants were used in the preparation by varying the pigment volume concentration 1 and $3 \%$. The volume solids of the prepared paint were $65-70 \%$. The paint was applied on the sandblasted (Sa 2.5) mild steel panel and evaluated after 10 days of curing at room temperature. The coating thickness was $100 \pm 10 \mu \mathrm{m}$.

Evaluation of corrosion-resistant property of the coating.-Total immersion test. - Coated panels of $10 \times 15 \mathrm{~cm}$ were exposed to $3 \% \mathrm{NaCl}$ for a period of 90 days. The performance of the coating was examined visually for various immersion periods.

OCP measurements. - A glass tube of $1.2 \mathrm{~cm}$ diam was fixed on the coated steel panels with $\mathrm{m}$-seal adhesive so as to expose an area of $1 \mathrm{~cm}^{2}$. A solution of $3 \% \mathrm{NaCl}$ was taken in the glass tube, and the saturated calomel reference electrode was placed inside the glass tube. The open-circuit potential (OCP) of the coated steel was measured with respect to saturated calomel electrode (SCE) using a high input impedance voltmeter (HP 973 A).

EIS studies. - The electrochemical cell as described above with a platinum auxillary electrode inside the glass tube along with SCE reference electrode was used for EIS measurements. The assembly was connected to an Advanced Electrochemical System (PAR 2273). Impedance measurements were carried out using Powersine software for a frequency range of $100 \mathrm{kHz}$ to $0.1 \mathrm{~Hz}$ with an ac signal of amplitude of $20 \mathrm{mV}$ for a different immersion time in $3 \% \mathrm{NaCl}$. The impedance values were reproducible \pm 2 to $3 \%$.

The bode representations of the impedance data were analyzed with Zview software. When there was a single time constant, the impedance data were analyzed using the equivalent circuit

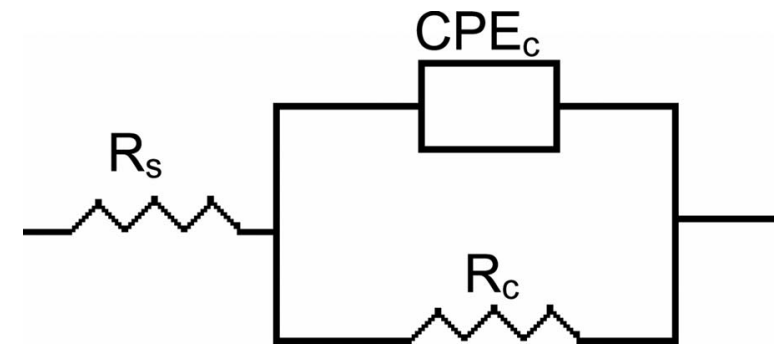

where $R_{\mathrm{S}}$ is the solution resistance, $R_{\mathrm{c}}$ is the coating resistance, and $\mathrm{CPE}_{\mathrm{c}}$ is the constant phase element corresponding to the capacitance of the coating.

When there exist two time constants the impedance data were analyzed using the equivalent circuit 


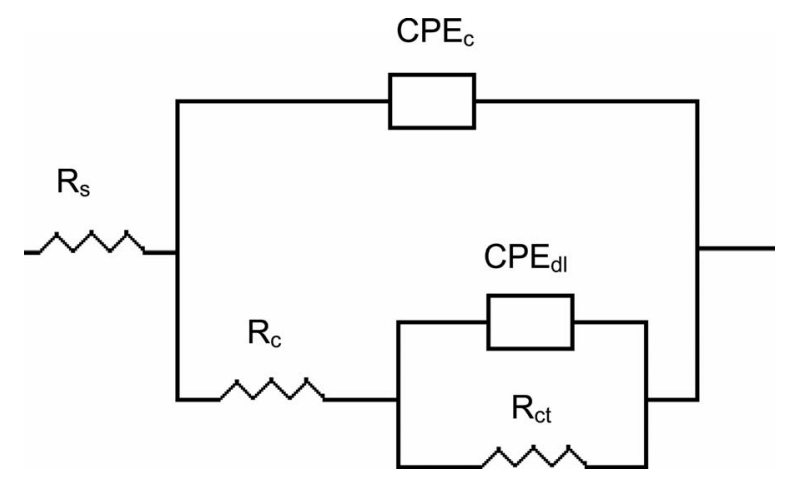

where $\mathrm{CPE}_{\mathrm{dl}}$ is the $\mathrm{CPE}$ corresponding to the interfacial doublelayer capacitance and $R_{\mathrm{ct}}$ is the charge transfer resistance due to the faradaic reaction at the interface.

For the description of a frequency-independent phase shift between an applied ac potential and its current response, a CPE is used that is defined in impedance representation as

$$
Z(Q)=Y_{0}^{-1}(j \omega)^{-n}
$$

where $Y_{0}$ is the CPE constant, $\omega$ is the angular frequency (in radians per second), $j^{2}=-1$ is the imaginary number, and $n$ is the CPE exponent $[n>0$, for ideal capacitance $Z(\mathrm{CPE})=C, n=1]$. The following equation used to convert $Y_{0}$ into $C$ is ${ }^{24}$

$$
C=Y_{0}\left(\omega_{m}^{\prime \prime}\right)^{n-1}
$$

where $C$ is either the coating resistance or the double-layer capacitance and $\omega_{m}^{\prime \prime}$ is the angular frequency at which $Z^{\prime \prime}$ is maximum.

XPS studies.-X-ray photoelectron spectra (XPS) of the samples were recorded on MultiLab 2000 (Thermofisher Scientific, UK) fitted with a twin anode $\mathrm{X}$-ray source using $\mathrm{Mg} \mathrm{K} \alpha$ radiation $(1253.6 \mathrm{eV})$. The sample was mounted on the stainless steel sample stubs using conducting silver paint (Agar Scientific Ltd., UK). The stub was initially kept in the preparatory chamber overnight for desorbing any volatile species at $10^{-9}$ mbar and was then introduced into the analysis chamber having a base pressure of 9.8 $\times 10^{-10}$ mbar for recording the spectra. High-resolution spectra av-
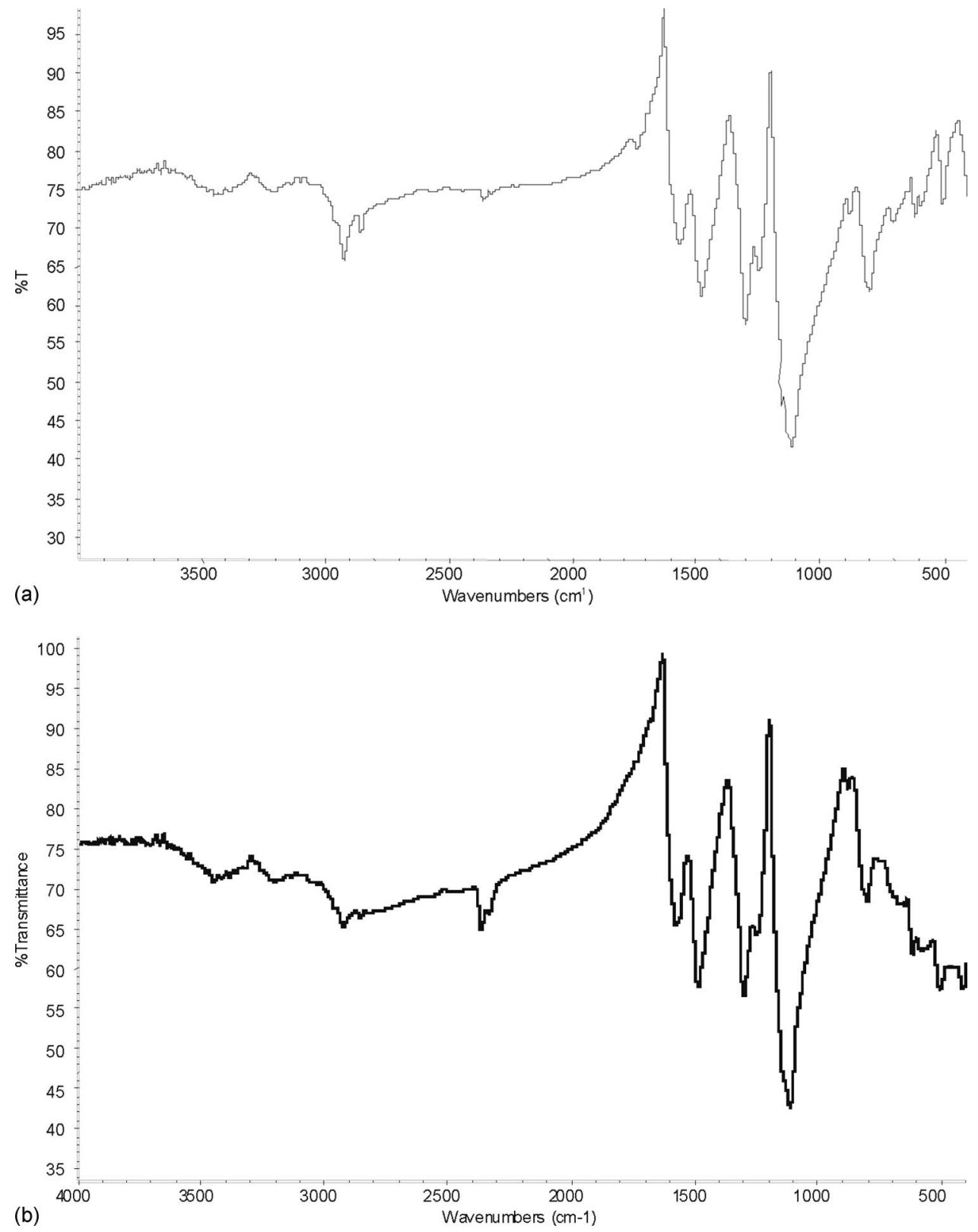

Figure 1. FTIR spectra of polyaniline: (a) PANI-Cl and (b) PANI-PO ${ }_{4}$. 


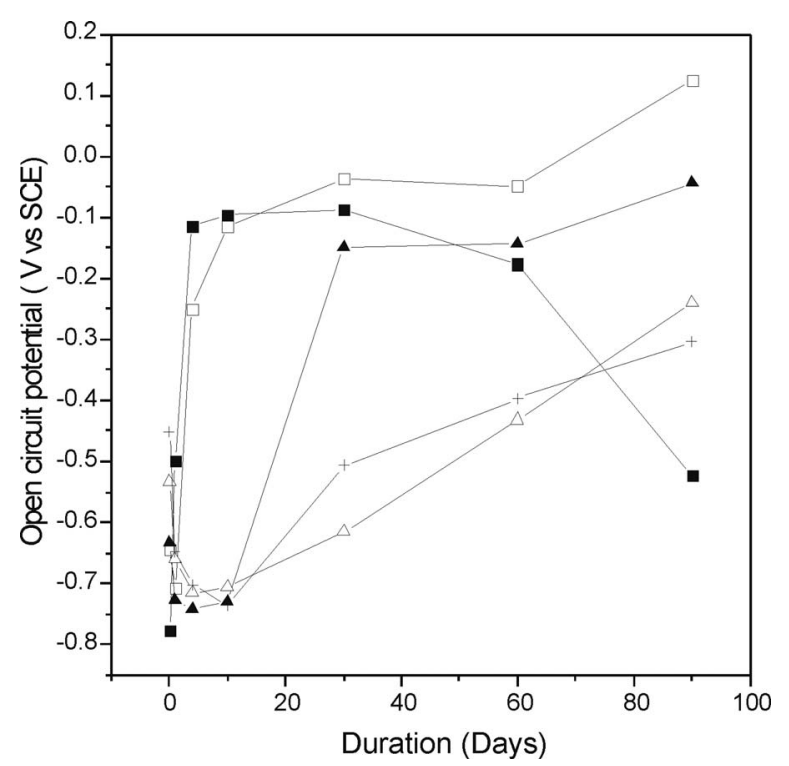

Figure 2. Variation of OCP with time for epoxy coal tar-coated steel in $3 \%$ $\mathrm{NaCl}$ solution: $\mathbf{a}$ epoxy coal tar; $\boldsymbol{\Delta} 1 \% \mathrm{PANI}_{-\mathrm{PO}}, \square 3 \% \mathrm{PANI}_{4} \mathrm{PO}_{4}, \triangle 1 \%$ PANI-Cl, and $+3 \%$ PANI-Cl.

eraged over five scans with a dwell time of $100 \mathrm{~ms}$ in steps of $0.05 \mathrm{eV}$ were obtained at pass energy of $20 \mathrm{eV}$ in constant analyzer energy mode. The binding energy was referenced with $\mathrm{C}$ (1s) at $284.98 \mathrm{eV}$ within accuracy of $\pm 0.05 \mathrm{eV}$. Sample analysis was done on the coating-removed area after 90 days exposure to $3 \% \mathrm{NaCl}$ solution.

\section{Results and Discussion}

Characterization of PANI pigments. - The FTIR spectra of PANI-Cl and PANI-PO ${ }_{4}$ are shown in Fig. 1a and b. The quinoid and benzenoid peaks for PANI-Cl and PANI-PO ${ }_{4}$ are found at 1561 and $1490 \mathrm{~cm}^{-1}$ and at 1562 and $1475 \mathrm{~cm}^{-1}$, respectively. ${ }^{25}$ The band around $1140 \mathrm{~cm}^{-1}$ for both polyanilines is assigned to a vibrating mode of $-\mathrm{NH}^{+}=$structure, which is formed during protonation. ${ }^{26}$ Besides, the band characteristics of conducting protonated form is observed at $\sim 1235 \mathrm{~cm}^{-1}$ for both the polymers due to $\mathrm{C}-\mathrm{N}^{+}$stretching vibration. ${ }^{27}$

The XRD pattern of both polymers showed an intense peak of $2 \theta$ value of $25^{\circ}$ and had a similar profile as reported for PANI in the literature. ${ }^{28,29}$ The conductivity value of $\mathrm{PANI}_{-} \mathrm{PO}_{4}$ was $2.17 \mathrm{~S} \mathrm{~cm}^{-1}$ and that of PANI-Cl was $0.02 \mathrm{~S} \mathrm{~cm}^{-1}$. The reported values of conductivity for PANI-PO ${ }_{4}{ }^{30}$ and PANI-Cl ${ }^{31}$ were 15.5 and $0.1 \mathrm{~S} \mathrm{~cm}^{-1}$, respectively. These results show that the prepared polyaniline pigments are conducting in nature and contain both benzenoid and quinoid moieties.

Total immersion tests.- The steel panels coated with 1 and 3\% PANI-PO $\mathrm{PO}_{4}$ and $3 \%$ PANI-Cl containing coatings have been found to be rust free after 90 days exposure. But in the case of coated panels with $1 \%$ PANI-Cl and plain epoxy coal tar have shown rust spots in few places after 90 days exposure.

OCP measurements. - The variation of OCP values with immersion time for studied systems is shown in Fig 2. The OCP values of the epoxy-coal tar coating panel are found to shift from $-0.7 \mathrm{~V}$ vs SCE to $-0.1 \mathrm{~V}$ vs SCE gradually up to 10 days immersion and remained in the same value up to 30 days and then decreased to

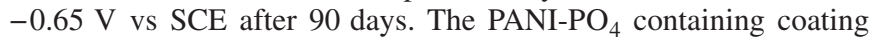
showed a shift of potential in noble direction from $-0.65 \mathrm{~V}$ vs SCE to $-0.1 \mathrm{~V}$ vs SCE for 10 days and remained at noble values higher than $-0.2 \mathrm{~V}$ vs SCE after 20 days immersion. But PANI-Clcontaining coatings showed a small shift in noble direction and at-

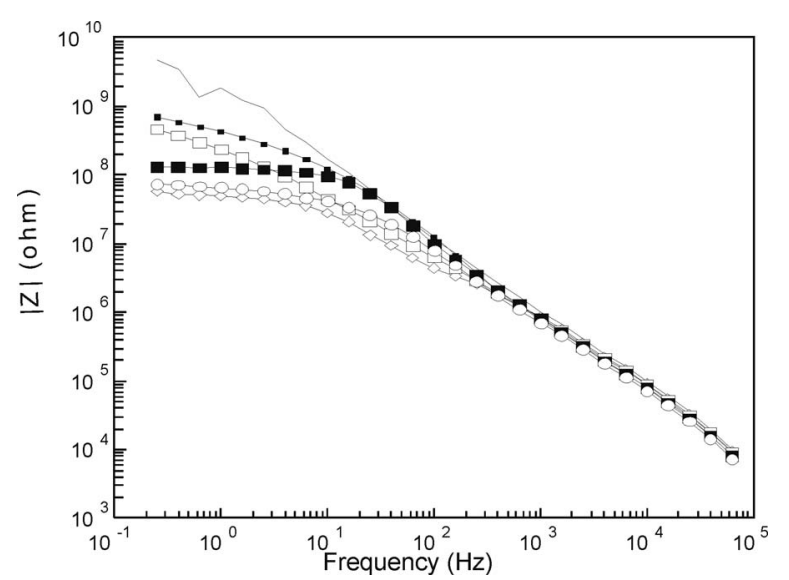

Figure 3. Impedance plots of epoxy-coal tar paint coated steel in $3 \%$ $\mathrm{NaCl}$ :- Initial, $\square 1$ day, $\square 4$ days, $\square 10$ days, $\bigcirc 30$ days, and $\diamond 90$ days.

tain about $-0.3 \mathrm{~V}$ vs SCE after 90 days immersion. On comparing the OCP values, the PANI-PO ${ }_{4}$-containing coatings have shown a larger shift in noble direction due to better passivation by polyaniline along with phosphate.

EIS studies. - The variation of impedance values with exposure period in 3\% $\mathrm{NaCl}$ for epoxy-coal tar-coated panel is shown in Fig. 3 , and the coating resistance $\left(R_{\mathrm{c}}\right)$ and coating capacitance $\left(C_{\mathrm{c}}\right)$ values are given in Table I. The $R_{\mathrm{c}}$ values remained at $1.07-7.7$ $\times 10^{8} \Omega \mathrm{cm}^{2}$ up to 30 days and decreased to $5.62 \times 10^{7} \Omega \mathrm{cm}^{2}$ after 90 days. However, the $C_{\mathrm{c}}$ values remained in the range of $1.0-5.44 \times 10^{-10} \mathrm{~F} \mathrm{~cm}^{-2}$ for the test period. Figures 4 and 5 show

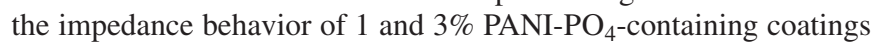
on steel in $3 \% \mathrm{NaCl}$, respectively. Table II gives the corresponding $R_{\mathrm{c}}$ and $C_{\mathrm{c}}$ values. Mostly, the $R_{\mathrm{c}}$ values for both the coatings are found to increase with immersion period and reach 1.38 $\times 10^{9} \Omega \mathrm{cm}^{2}$ in the case of $1 \%$ PANI-PO $_{4}$ and $1.05 \times 10^{9} \Omega \mathrm{cm}^{2}$ in the case of $3 \%$ PANI- $\mathrm{PO}_{4}$-containing coatings. These values are nearly 2 orders high in comparison to that of plain epoxy-coal tar coating. The capacitance values for both coatings with $\mathrm{PANI}^{-\mathrm{PO}_{4}}$ remain less than $1 \times 10^{-10} \mathrm{~F} \mathrm{~cm}^{-2}$.

Figures 6 and 7 show the impedance variation of PANI-Clcontaining coatings on steel in $3 \% \mathrm{NaCl}$. In the case of $1 \%$ PANICl-containing coating, the impedance data showed the existence of two time constants, and hence, they have been fitted with the corresponding equivalent circuit containing two $R$ and $C$ described in the Experimental section where as in the case of 3\% PANI-Clcontaining coating, existence of two time constants were noted initially, which disappeared after four days of immersion. This suggests the onset of corrosion at the earlier instances of both 1 and 3\% PANI-Cl-containing coatings. Because of the passivating ability of PANI, the corrosion was suppressed and passivated in the case of $3 \%$ PANI-Cl-containing coating. Hence, this resulted in the existence of a single time constant for subsequent exposure periods.

Table I. Impedance parameters of epoxy-coal tar paint-coated steel in $3 \% \mathrm{NaCl}$.

\begin{tabular}{lcc}
$\begin{array}{l}\text { Time } \\
\text { days }\end{array}$ & $\begin{array}{c}R_{\mathrm{c}} \\
\Omega \mathrm{cm}^{2}\end{array}$ & $\begin{array}{c}C_{\mathrm{c}} \\
\mathrm{F} \mathrm{cm}^{-2}\end{array}$ \\
\hline Initial & $1.29 \times 10^{10}$ & $1.03 \times 10^{-10}$ \\
1 & $7.71 \times 10^{8}$ & $1.51 \times 10^{-10}$ \\
4 & $6.49 \times 10^{8}$ & $4.60 \times 10^{-10}$ \\
10 & $1.07 \times 10^{8}$ & $5.44 \times 10^{-10}$ \\
30 & $6.49 \times 10^{7}$ & $4.60 \times 10^{-10}$ \\
90 & $5.62 \times 10^{7}$ & $2.22 \times 10^{-10}$
\end{tabular}




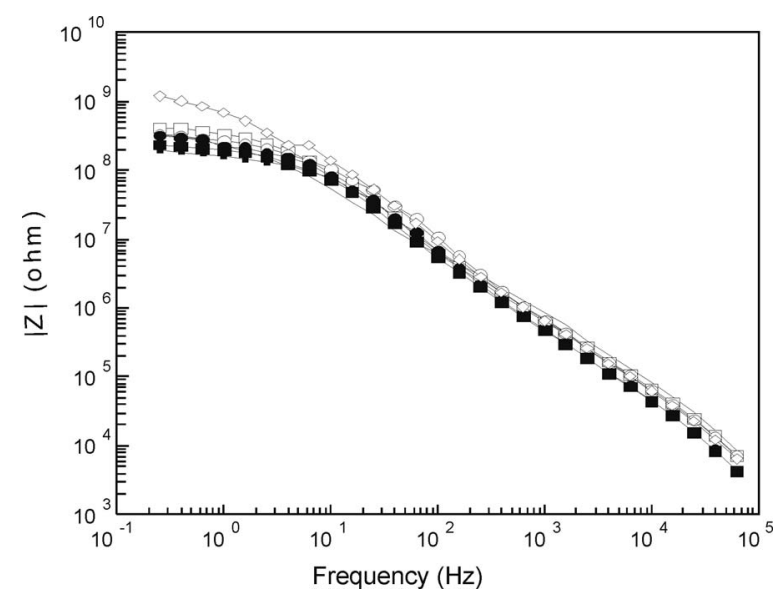

Figure 4. Impedance plots of $1 \% \mathrm{PANI}^{-\mathrm{PO}_{4}}$ containing epoxy-coal tar paint-coated steel in $3 \% \mathrm{NaCl}$ :- Initial, $\square 1$ day, $\square 4$ days, $\square 10$ days, $\bigcirc$ 30 days, 60 days, and $\diamond 90$ days.

Whereas in the case of $1 \%$ PANI-Cl-containing coating, the existence of two time constants were observed for the entire test period. The coating resistance $R_{\mathrm{c}}$, coating capacitance $C_{\mathrm{c}}$, charge transfer resistance $R_{\mathrm{ct}}$, and double-layer capacitance $C_{\mathrm{dl}}$ obtained from these figures are given in Table III. Even though there is a slight increase in $R_{\mathrm{ct}}$ values for $1 \%$ PANI-Cl-containing coating, the $R_{\mathrm{c}}$ value is decreased from $5.95 \times 10^{8}$ to $4.62 \times 10^{6} \Omega \mathrm{cm}^{2}$ after 90 days immersion, and this value is slightly less than that of the plain epoxy-

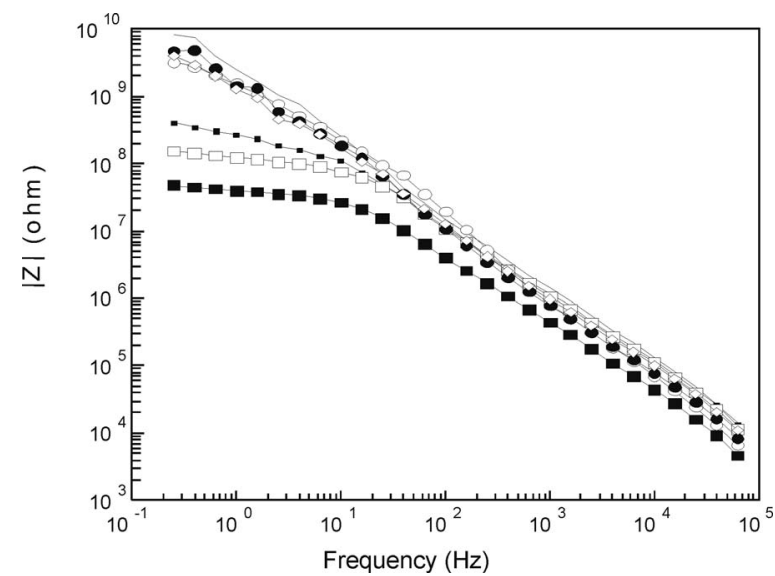

Figure 5. Impedance plots of $3 \% \mathrm{PANI}^{-\mathrm{PO}_{4}}$ containing epoxy-coal tar paint-coated steel in $3 \% \mathrm{NaCl}$ :-Initial, $\square 1$ day, $\square 4$ days; $\square 10$ days, $\bigcirc$ 30 days, 60 days, and $\diamond 90$ days.

\begin{tabular}{|c|c|c|c|c|}
\hline \multicolumn{5}{|c|}{$\begin{array}{l}\text { Table II. Impedance parameters of } 1 \text { and } 3 \% \text { PANI-PO }_{4} \text { contain- } \\
\text { ing epoxy-coal tar paint-coated steel in } 3 \% \mathrm{NaCl} \text {. }\end{array}$} \\
\hline \multirow[b]{2}{*}{$\begin{array}{l}\text { Time } \\
\text { Days }\end{array}$} & \multicolumn{2}{|c|}{$1 \% \mathrm{PANI}^{-\mathrm{PO}_{4}}$} & \multicolumn{2}{|c|}{$3 \% \mathrm{PANI}^{-\mathrm{PO}_{4}}$} \\
\hline & $\begin{array}{c}R_{\mathrm{c}} \\
\Omega \mathrm{cm}^{2}\end{array}$ & $\begin{array}{c}C_{\mathrm{c}} \\
\mathrm{F} \mathrm{cm}^{-2}\end{array}$ & $\begin{array}{c}R_{\mathrm{c}} \\
\Omega \mathrm{cm}^{2}\end{array}$ & $\begin{array}{c}C_{\mathrm{c}} \\
\mathrm{F} \mathrm{cm}\end{array}$ \\
\hline Initial & $3.17 \times 10^{8}$ & $3.02 \times 10^{-10}$ & $2.59 \times 10^{10}$ & $7.37 \times 10^{-11}$ \\
\hline 1 & $1.81 \times 10^{8}$ & $2.21 \times 10^{-10}$ & $3.86 \times 10^{8}$ & $1.40 \times 10^{-10}$ \\
\hline 4 & $4.08 \times 10^{8}$ & $2.15 \times 10^{-10}$ & $1.37 \times 10^{8}$ & $1.46 \times 10^{-10}$ \\
\hline 10 & $2.26 \times 10^{8}$ & $2.81 \times 10^{-10}$ & $4.31 \times 10^{7}$ & $3.74 \times 10^{-10}$ \\
\hline 30 & $3.19 \times 10^{8}$ & $1.73 \times 10^{-10}$ & $3.55 \times 10^{9}$ & $8.64 \times 10^{-11}$ \\
\hline 60 & $3.08 \times 10^{8}$ & $2.43 \times 10^{-10}$ & $1.22 \times 10^{10}$ & $1.11 \times 10^{-10}$ \\
\hline 90 & $1.38 \times 10^{9}$ & $1.65 \times 10^{-10}$ & $1.05 \times 10^{9}$ & $1.15 \times 10^{-10}$ \\
\hline
\end{tabular}

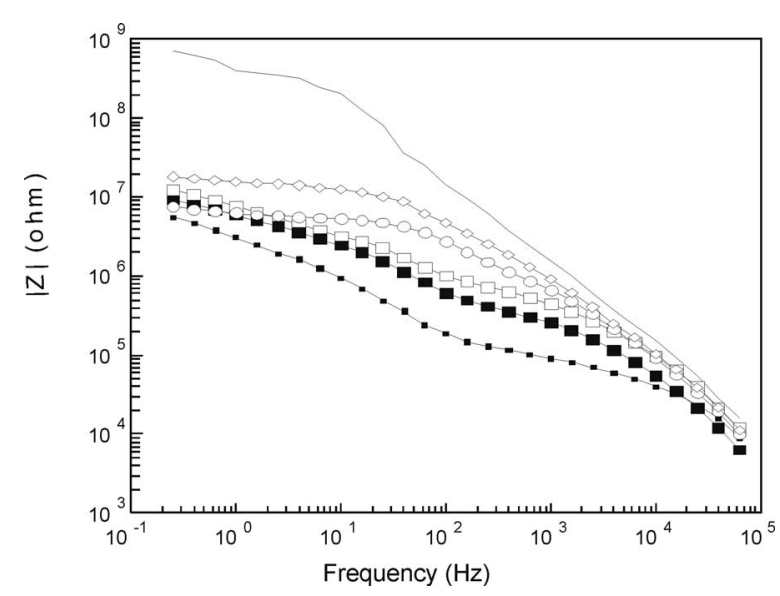

Figure 6. Impedance plots of $1 \%$ PANI-Cl containing epoxy-coal tar paintcoated steel in $3 \% \mathrm{NaCl}$ :- Initial, $\square 1$ day, $\square 4$ days, $\square 10$ days, $\bigcirc$ 30 days, and $\diamond 90$ days.

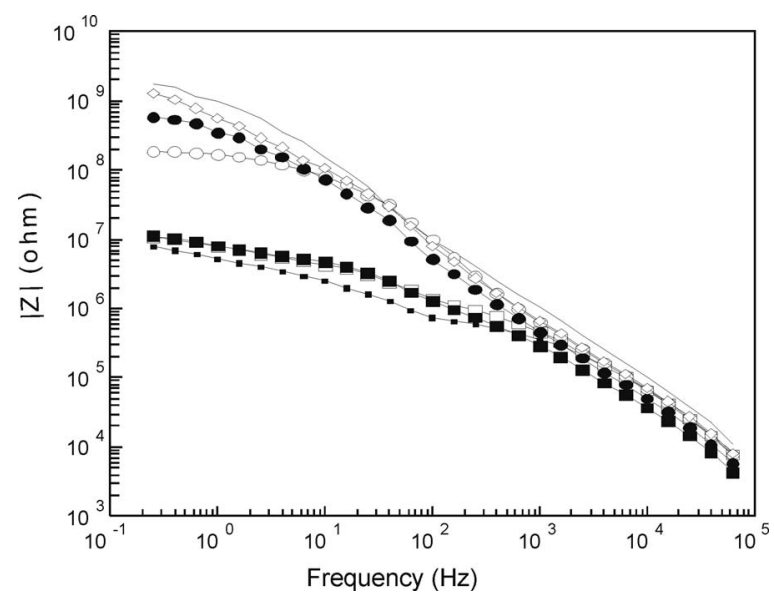

Figure 7. Impedance plots of $3 \%$ PANI-Cl containing epoxy-coal tar paintcoated steel in $3 \% \mathrm{NaCl}$ :- Initial, $\square 1$ day, $\square 4$ days, $\square 10$ days, $\bigcirc$ 30 days, 60 days, and $\diamond 90$ days.

Table III. Impedance parameters of 1 and 3\% PANI-Cl containing epoxy-coal tar paint-coated steel in $3 \% \mathrm{NaCl}$.

\begin{tabular}{lcccc} 
& \multicolumn{4}{c}{$1 \%$ PANI-Cl } \\
\cline { 2 - 5 } Time & $\begin{array}{c}R_{\mathrm{c}} \\
\Omega \mathrm{cm}^{2}\end{array}$ & $\begin{array}{c}C_{\mathrm{c}} \\
\mathrm{F} \mathrm{cm}\end{array}$ & $\begin{array}{c}R_{\mathrm{ct}} \\
\Omega \mathrm{cm}^{2}\end{array}$ & $\begin{array}{c}C_{\mathrm{dl}} \\
\mathrm{F} \mathrm{cm}\end{array}$ \\
\hline Days & $5.95 \times 10^{8}$ & $9.91 \times 10^{-11}$ & - & - \\
Initial & $7.02 \times 10^{4}$ & $2.73 \times 10^{-10}$ & $9.54 \times 10^{6}$ & $5.71 \times 10^{-8}$ \\
1 & $7.18 \times 10^{5}$ & $1.62 \times 10^{-10}$ & $1.18 \times 10^{7}$ & $1.62 \times 10^{-8}$ \\
4 & $4.30 \times 10^{5}$ & $1.74 \times 10^{-8}$ & $1.03 \times 10^{7}$ & $1.74 \times 10^{-8}$ \\
10 & $9.47 \times 10^{5}$ & $1.84 \times 10^{-10}$ & $7.04 \times 10^{6}$ & $1.02 \times 10^{-9}$ \\
30 & $1.43 \times 10^{6}$ & $1.95 \times 10^{-10}$ & $5.43 \times 10^{6}$ & $1.95 \times 10^{-10}$ \\
60 & $4.62 \times 10^{6}$ & $1.63 \times 10^{-10}$ & $1.17 \times 10^{7}$ & $4.22 \times 10^{-10}$ \\
90 &
\end{tabular}

\begin{tabular}{lcccc} 
& \multicolumn{4}{c}{$3 \%$ PANI-Cl } \\
Initial & $1.98 \times 10^{9}$ & $1.32 \times 10^{-10}$ & - & - \\
1 & $8.79 \times 10^{6}$ & $1.12 \times 10^{-8}$ & $4.47 \times 10^{5}$ & $3.18 \times 10^{-10}$ \\
4 & $8.36 \times 10^{5}$ & $3.56 \times 10^{-10}$ & $9.21 \times 10^{6}$ & $3.53 \times 10^{-9}$ \\
10 & $9.83 \times 10^{6}$ & $1.62 \times 10^{-10}$ & - & - \\
30 & $1.79 \times 10^{8}$ & $1.86 \times 10^{-10}$ & - & - \\
60 & $5.80 \times 10^{8}$ & $2.78 \times 10^{-10}$ & - & - \\
90 & $1.68 \times 10^{9}$ & $1.94 \times 10^{-10}$ & - & -
\end{tabular}




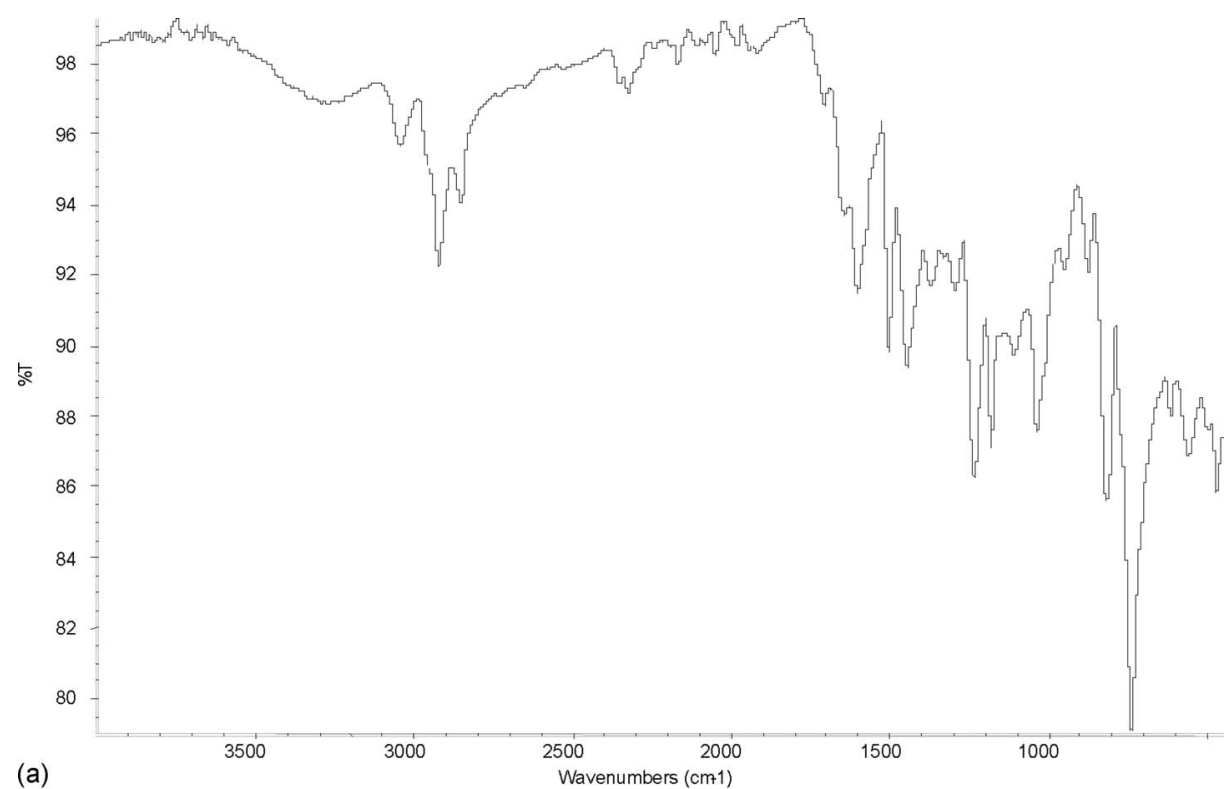

Figure 8. FTIR spectra of PANI pigmented epoxy-coal tar coating before exposure to $3 \% \mathrm{NaCl}$ solution: (a)

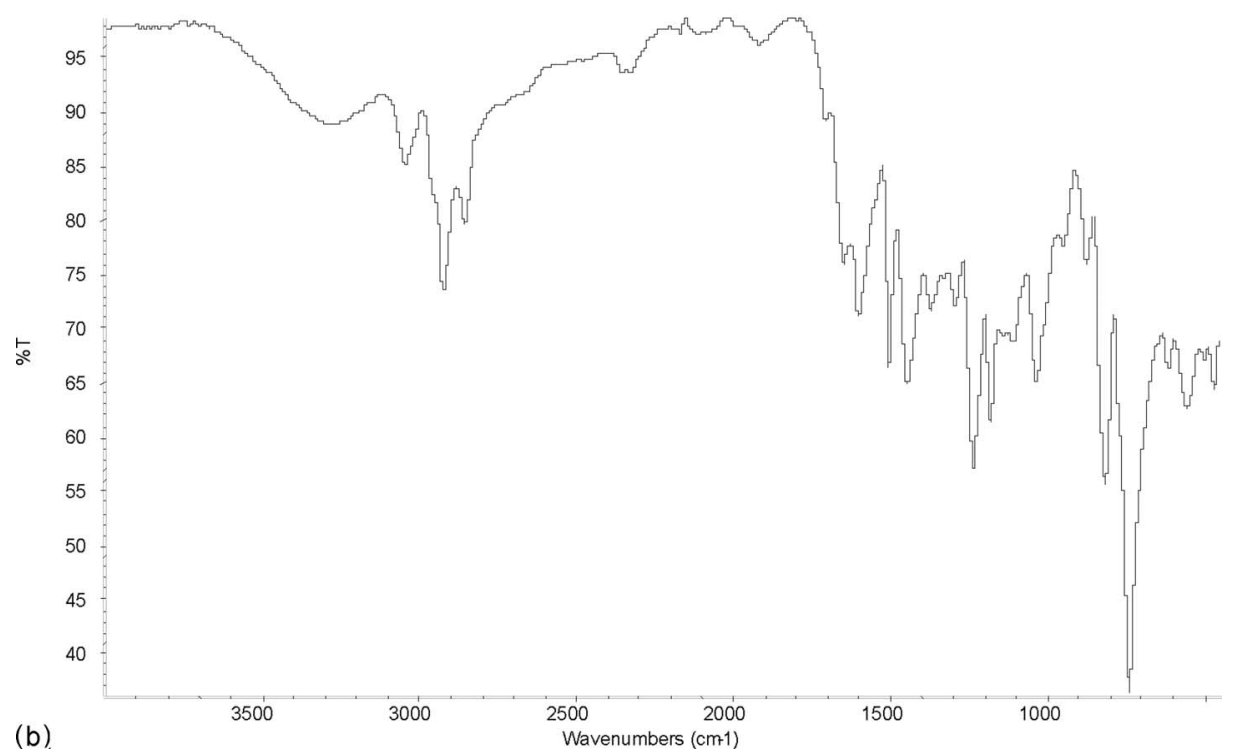
$\mathrm{PANI}_{-} \mathrm{PO}_{4}$ and (b) PANI-Cl.

(b)

coal tar-coated system. But in the case of coating containing $3 \%$ PANI-Cl, the $R_{\mathrm{c}}$ values are found to be decreased to 8.36 $\times 10^{5} \Omega \mathrm{cm}^{2}$ after four days immersion and afterward the $R_{\mathrm{c}}$ values are increased to $1.68 \times 10^{9} \Omega \mathrm{cm}^{2}$ after 90 days immersion, which is nearly 2 orders high in comparison to that of plain epoxy-coal tar coating. These studies have clearly shown that the coatings containing $\mathrm{PANI}-\mathrm{PO}_{4}$ and PANI-Cl are found to be more protective than that of plain epoxy-coal tar coating.

The OCP values of PANI-PO $4^{-}$and PANI-Cl-containing coatings on steel are found to be in the noble range in comparison to that of plain epoxy-coal tar coating. Such high positive OCP values for PANI-coated iron have been reported in sodium chloride solution. ${ }^{4,6}$ This positive shift of potential is mainly attributed to the passivation of iron surface by PANI due to its redox property. ${ }^{32-34}$ On comparing the shift of OCP values, the $\mathrm{PANI}-\mathrm{PO}_{4}$-containing coatings have exhibited very high noble values due to the reinforced passivation effect of both PANI and phosphate. It has been well established by de Souza et al. ${ }^{8}$ and da Silva et al. ${ }^{10,22}$ from Raman spectroscopy that the dopants present in the polyaniline coating form a protective iron-dopant complex layer on the iron surface. But in the case of
PANI-Cl, the formed iron-dopant complex is less protective in nature and, hence, the small shift of OCP value is mainly due to redox property of PANI.

Besides the shift of OCP values for $\mathrm{PANI}_{-} \mathrm{PO}_{4}$-containing coating on steel, an increased value of $R_{\mathrm{c}}$ is observed for longer exposure time. These $R_{\mathrm{c}}$ values are nearly 2 orders higher in comparison to that of plain epoxy-coal tar coating. Similarly, the coating containing 3\% PANI-Cl has shown the $R_{\mathrm{c}}$ value of 2 orders higher than that of plain epoxy-coal tar coating. These high $R_{\mathrm{c}}$ values indicate that PANI present in the coating is able to protect steel. Earlier scanning electron microscope and XPS studies have shown that polyaniline forms a passive oxide layer and the oxide layer formed by PANI on the iron surface is mainly of an $\mathrm{Fe}_{2} \mathrm{O}_{3}$ layer. ${ }^{35}$ The mechanism of protection of iron by doped PANI is shown that PANI [Emeraldine salt (ES)] and PANI [Leuco base (LB)] redox couple has been regarded as being responsible for establishing the potential of iron in the passive region. ${ }^{32,33}$ The PANI (LB) that has been formed is cyclically oxidized to PANI (ES) again by the reduction of oxygen so that the potential of iron is always maintained in the passive region. ${ }^{36}$ 

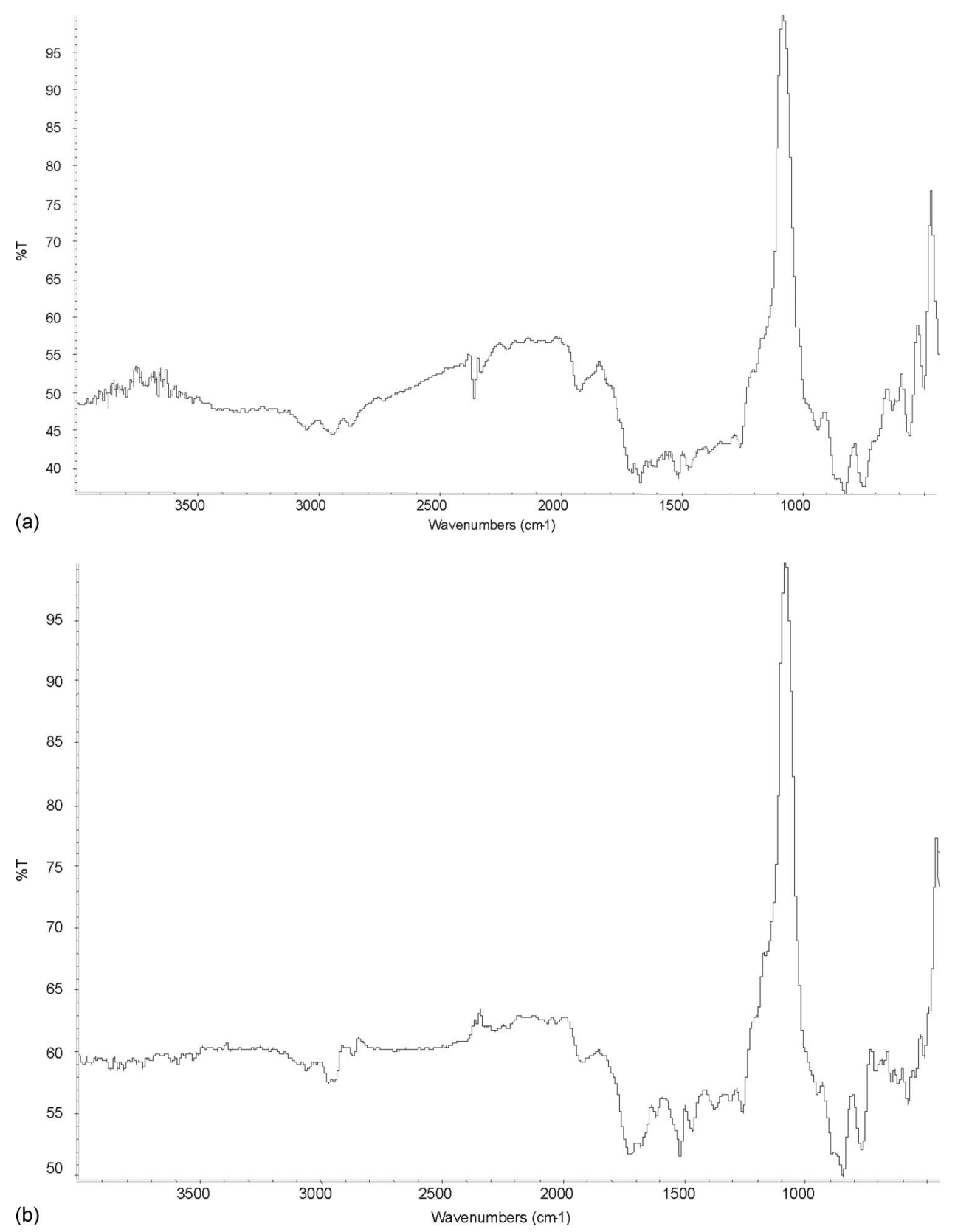

Figure 9. FTIR spectra of PANI pigmented epoxy-coal tar coating after exposure to $3 \% \mathrm{NaCl}$ for 90 days: (a) $\mathrm{PANI}_{-} \mathrm{PO}_{4}$ and (b) PANI-Cl.

It has been reported that the peaks around 1235 and $1140 \mathrm{~cm}^{-1}$ are due to $\mathrm{C}-\mathrm{N}^{+}$vibration of the polaron structure and vibration mode of $-\mathrm{NH}^{+}=$structure, which formed during protonation are indicative of the conducting nature of polyaniline. ${ }^{26}$ Figures 8 and 9 show the FTIR spectra of PANI-containing coating before and after exposure to $\mathrm{NaCl}$ solution. It can be seen that the FTIR spectra of coated samples after exposure to $\mathrm{NaCl}$ solution do not show the peaks around 1235 and $1140 \mathrm{~cm}^{-1}$, which indicate the change of the conducting state of PANI due to dedoping. Furthermore, the presence of polyaniline on the iron surface beneath the paint coating has been confirmed by the FTIR spectroscopic studies of the paint removed area after exposure to $\mathrm{NaCl}$ solution for 90 days. Figure 10 shows the FTIR spectra of the above-mentioned system. In the spectra, the characteristic peaks of polyaniline are observed. Besides, it is found that a blueshift of quinoid and benzenoid vibration is due to the interaction of PANI and iron salts as reported by Dimitriev. ${ }^{37}$ Furthermore, Izumi et al. ${ }^{38}$ have proved by Raman and UV spectroscopy that $\mathrm{Fe}$ (III) forms complexes with PANI. Hence, the corrosion protection offered by PANI in epoxy-coal tar system may also be due to the formation of Fe-PANI complex beneath the paint coating exposed to $\mathrm{NaCl}$ solution along with passive oxide film and iron phosphate salt layer. Such type of the formation of the metal ionPANI complex has been reported to offer corrosion protection as shown by Fahlman et al. ${ }^{39}$ and Epstein et al. ${ }^{40}$ on Al-Cu alloys due to the formation of $\mathrm{Cu}-\mathrm{PANI}$ complex.

XPS studies.- XPS data of the surface beneath the coating removed area after 90 days exposure to $3 \% \mathrm{NaCl}$ solution are shown in Fig. 11 and 12. The presence of iron peaks at 723.61 and $709.6 \mathrm{eV}$ has been related to the presence of the $\mathrm{Fe}_{2} \mathrm{O}_{3}$ layer. ${ }^{41}$ The reported binding energies for the quinoid amine $(-\mathrm{N}=)$ benzenoid amine $(-\mathrm{NH}-)$, the positively charged nitrogen $\left(\mathrm{N}^{+}\right)$are 398.2 , 399.4 , and above $400 \mathrm{eV}$, respectively. ${ }^{42}$ The observed nitrogen beak at $399.8 \mathrm{eV}$ indicates the presence of dedoped polyaniline on the surface. The XPS results indicate the presence of the oxide layer along with a dedoped polyaniline layer on the surface. Besides, the presence of chlorine and phosphorous in traces has also been indicated. Hence, the oxide layer or Fe-PANI complex layer protect the 

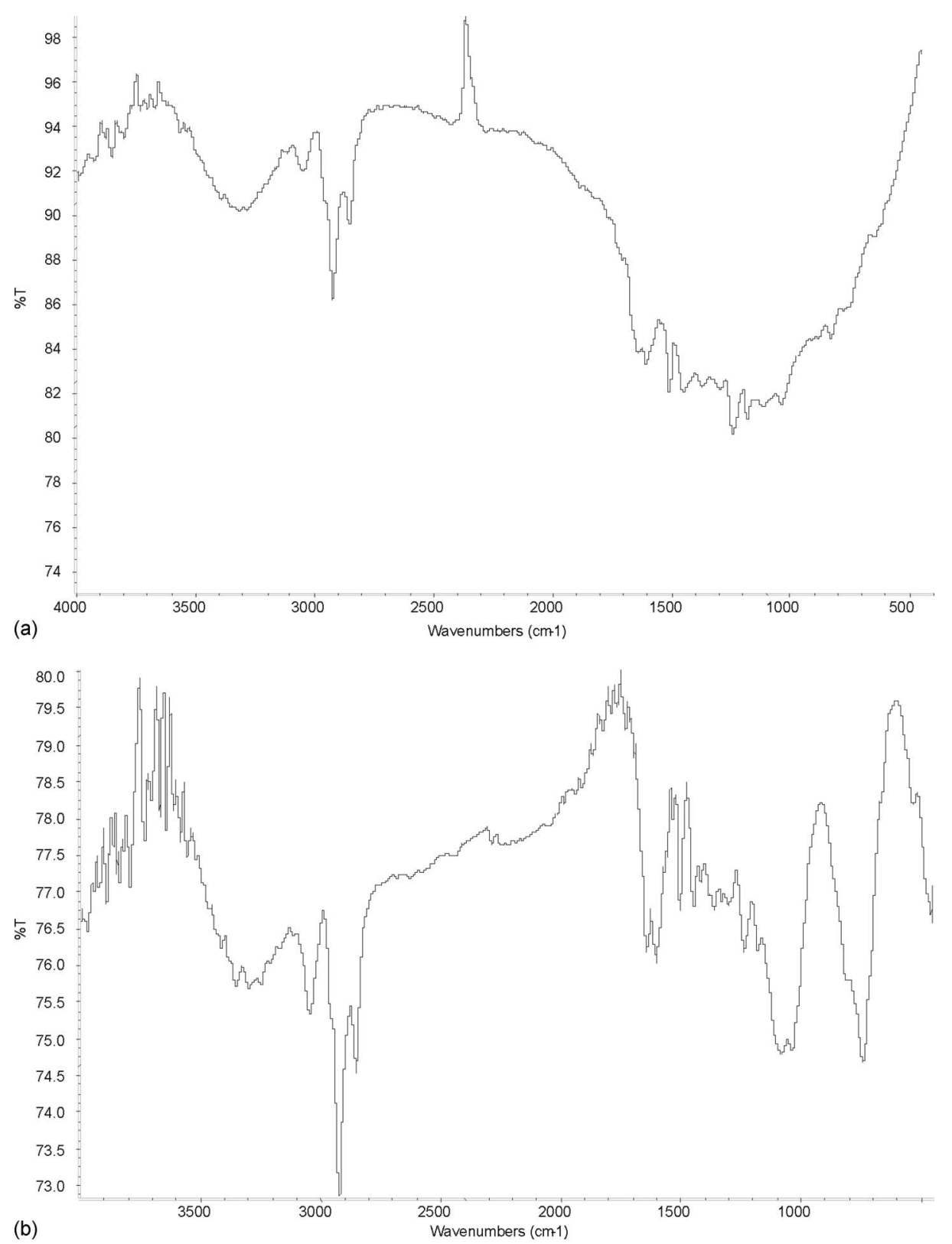

Figure 10. FTIR spectra of PANI pigmented epoxy-coal tar coating on paint removed area after exposure to $3 \% \mathrm{NaCl}$ solution for 90 days: (a) PANI-PO 4 and (b) PANI-Cl. iron surface from corrosion. Earlier XPS studies of PANI-coated steel showed similar spectra. ${ }^{43}$ The details of percentage contribution to each element are given in Table IV.

\section{Conclusion}

Phosphate- and chloride-doped polyaniline have been synthesized by chemical polymerization methods. The corrosion protection property of the epoxy-coal tar coatings containing these polymers has been studied by OCP and the EIS method in 3\% $\mathrm{NaCl}$ solution. Coatings containing 1 and $3 \%$ phosphate-doped PANI and $3 \%$ chloride-doped PANI were found to be highly corrosion resistant. The higher corrosion protection ability of phosphate-doped PANI is due to redox property of PANI along with the formation of ironPANI complex and secondary layer of iron-phosphate layer on steel.

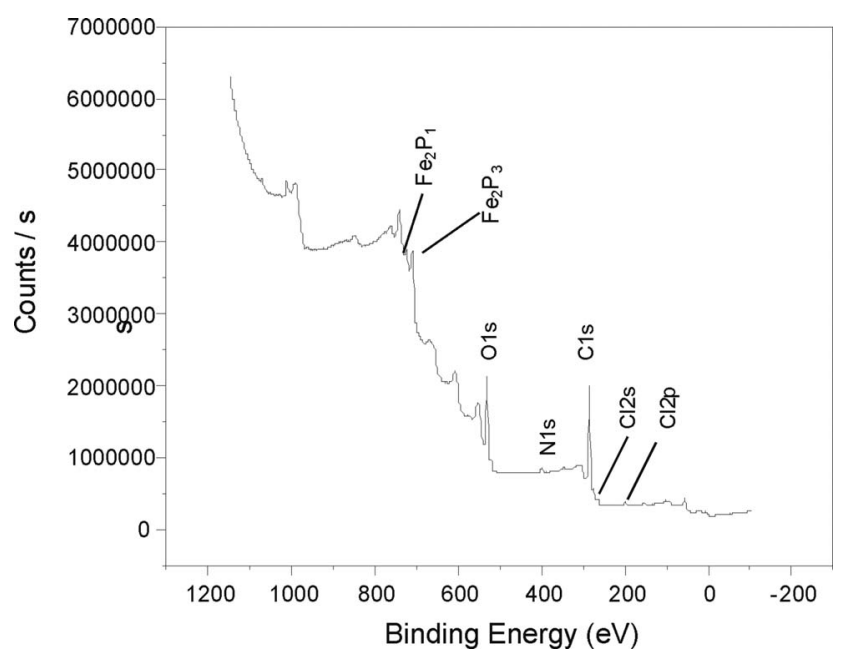

Figure 11. XPS spectra of PANI-Cl pigmented epoxy-coal tar coating on paint removed area after exposure to $3 \% \mathrm{NaCl}$ solution for 90 days. 


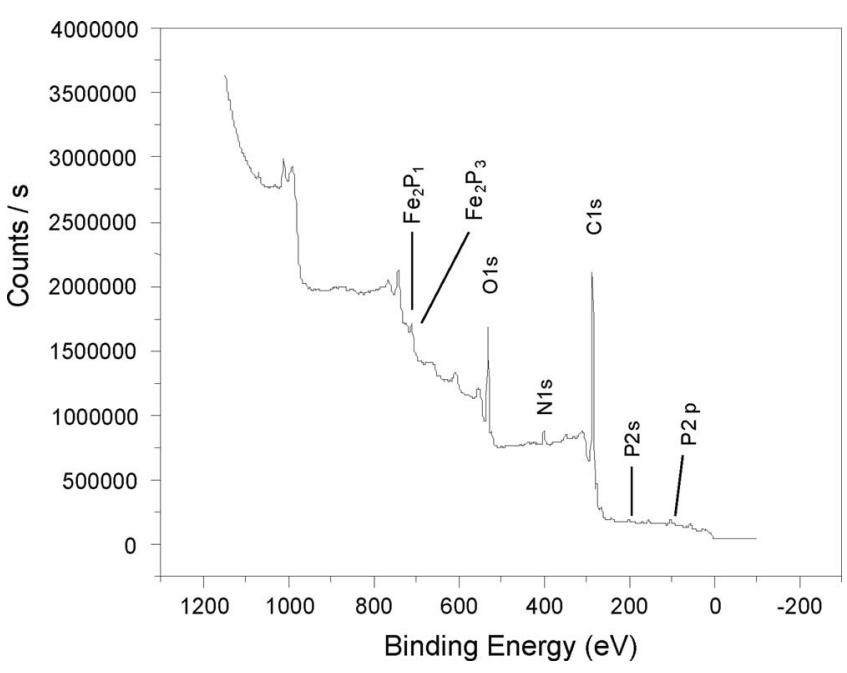

Figure 12. XPS spectra of $\mathrm{PANI}-\mathrm{PO}_{4}$ pigmented epoxy-coal tar coating on paint removed area after exposure to $3 \% \mathrm{NaCl}$ solution for 9 days.

\begin{tabular}{|c|c|c|c|c|}
\hline \multirow[b]{2}{*}{ Element } & \multicolumn{2}{|c|}{$\mathrm{PANI}-\mathrm{PO}_{4}$ System } & \multicolumn{2}{|c|}{ PANI-Cl System } \\
\hline & $\begin{array}{l}\text { Peak B.E. } \\
(\mathrm{eV})\end{array}$ & At $\%$ & $\begin{array}{c}\text { Peak B.E. } \\
(\mathrm{eV})\end{array}$ & At $\%$ \\
\hline Carbon (C 1s) & 284.97 & 65.82 & 284.94 & 74.4 \\
\hline Nitrogen (N 1s) & 399.89 & 2.81 & 399.8 & 1.5 \\
\hline Oxygen (O 1s) & 536.69 & 2.1 & 530.6 & 3.72 \\
\hline Iron $\left(\mathrm{Fe}_{2} \mathrm{P}_{1}\right)$ & 722.61 & - & 722.5 & - \\
\hline Iron $\left(\mathrm{Fe}_{2} \mathrm{P}_{3}\right)$ & 709.6 & - & 709.4 & - \\
\hline
\end{tabular}

\section{Acknowledgment}

The authors thank the director of CECRI for his kind permission to carry out the work.

Central Electrochemical Research Institute assisted in meeting the publication costs of this article.

\section{References}

1. P. J. Kinlen, V. Menon, and Y. Ding, J. Electrochem. Soc., 146, 3690 (1999).

2. P. J. Kinlen, J. Ding, and D. C. Silverman, Corrosion (Houston), 58, 490 (2002).

3. W. K. Lu, R. L. Elsenbaumer, and B. Wessling, Synth. Met., 71, 2163 (1995).
4. A. Talo, P. Passiniemi, O. Forsen, and S. Ylasaari, Synth. Met., 85, 1333 (1997). 5. D. E. Tallmen, Y. Pae, and G. P. Bierwagen, Corrosion (Houston), 55, 779 (1999). 6. J. R. Santos, Jr., L. H. C. Mattoso, and A. J. Motheo, Electrochim. Acta, 43, 309 (1998)

7. W. S. Araujo, I. C. P. Margarit, M. Ferreira, O. P. Mattos, and P. Lema Neto, Electrochim. Acta, 46, 1307 (2001)

8. S. de Souza, J. E. P. da Silva, S. I. C. de Torresi, M. L. A. Temperini, and R. M. Torresi, Electrochem. Solid-State Lett., 4, B27 (2001).

9. M. M. Poporic, B. N. Grgur, and V. B. N. Stankovic, Prog. Org. Coat., 52, 359 (2005).

10. J. E. P. daSilva, S. I. C. deTorresi, and R. M. Torresi, Corros. Sci., 47, 811 (2005).

11. S. Sathiyanarayanan, S. Muthukrishnan, G. Venkatachari, and D. C. Trivedi, Prog. Org. Coat., 53, 297 (2005)

12. A. B. Samui, A. S. Patenkar, J. Rengarajan, and P. C. Deb., Prog. Org. Coat., 47, 1 (2003).

13. A. J. Dominis, G. M. Spinks, and G. G. Wallace, Prog. Org. Coat., 48, 43 (2003).

14. S. Sathiyanarayanan, S. Muthukrishnan, and G. Venkatachari, Prog. Org. Coat., 54, 5 (2006).

15. N. Plesu, G. Ilia, A. Pascariu, and G. Vlase, Synth. Met., 156, 230 (2006).

16. S. Sathiyanarayanan, S. Muthukrishnan, and G. Venkatachari, Electrochim. Acta, 51, 6313 (2006)

17. S. Sathiyanarayanan, S. Muthukrishnan, and G. Venkatachari, J. Appl. Polym. Sci., 102, 3994 (2006)

18. S. Syed Azim, S. Sathiyanarayanan, and G. Venkatachari, Prog. Org. Coat., 56, 154 (2006).

19. A. B. Samui and S. M. Phadnis, Prog. Org. Coat., 54, 297 (2005).

20. G. Williams, A. Gabriel, A. Cook, and H. N. McMurray, J. Electrochem. Soc. 153, B425 (2006).

21. Y. Chen, X. H. Wang, J. Li, J. L. Lu, and F. S. Wang, Corros. Sci., 49, 3052 (2007)

22. J. E. P. da Silva, S. I. C. de Torresi, and R. M. Torresi, Prog. Org. Coat., 58, 33 (2007).

23. X. Zhang, F. Wang, and Y. Du, Prog. Org. Coat., 53, 302 (2005).

24. F. Mansfeld, Corrosion (Houston), 37, 301 (1981).

25. P. Liu, W. Liu, and Q. Xue, Mater. Chem. Phys., 87, 109 (2004).

26. J. C. Chiang and A. G. Mac Diarmid, Synth. Met., 13, 193 (1986).

27. P. S. Khiew, N. H. Huang, S. Radiman, and M. S. Ahmed, Mater. Lett., 58, 109 (2004)

28. M. Wan and J. Li, J. Polym. Sci., A36, 2799 (1998).

29. T. Abdiryum, Z. X. Gang, and R. Jamal, Mater. Chem. Phys., 90, 367 (2005).

30. N. Bilmore, J. Stejskal, M. Trchora, and J. Proks, Polymer, 42, 47 (2006).

31. C. Zhan, J. Zeng, Y. Li, X. Yang, and J. Qin, Synth. Met., 101, 731 (1999).

32. M. C. Bernard, A. Hugot-Le-Goff, S. Joiret, N. N. Ginh, and N. N. Toan, J. Electrochem. Soc., 146, 995 (1999)

33. T. Schauer, A. Joos, L. Dulog, and C. D. Eisenbach, Prog. Org. Coat., 33, 20 (1998).

34. B. Wessling and J. Posdorfer, Electrochim. Acta, 44, 2139 (1999).

35. B. Wessling, Synth. Met., 5, 1313 (1997).

36. R. Gasparac and R. C. Martin, J. Electrochem. Soc., 148, B138 (2001)

37. O. P. Dimitriev, Synth. Met., 142, 299 (2004)

38. C. M. S. Izumi, V. R. L. Constantino, A. M. C. Ferreira, and M. L. A. Tenperini, Synth. Met., 156, 654 (2006).

39. M. Fahlman, X. Crispin, H. Guan, S. Li, J. A. O. Smallfield, Y. Wei, and A. J. Epstein, Polym. Prepr. (Am. Chem. Soc. Div. Polym. Chem.), 41, 1753 (2000).

40. A. J. Epstein, J. A. O. Smallfield, H. Guan, and M. Fahlman, Synth. Met., 102, 1374 (1999)

41. Y. Chen, X. H. Wang, J. Li, J. L. Lu, and F. S. Wang, Corros. Sci, 49, 3052 (2007).

42. E. T. Kang, K. G. Neoh, K. L. Tan, and H. S. Nalwa, Handbook of Conductive Molecules and Polymers, Vol. 3, p. 121, John Wiley \& Sons, Chichester (1997).

43. N. M. Martgak and P. McAndrew, Corros. Sci., 49, 3826 (2007). 